\title{
“DOS DIREITOS E GARANTIAS FUNDAMENTAIS" NOS TEXTOS CONSTITUCIONAIS DOS ESTADOS-MEMBROS E OS LIMITES DO PODER CONSTITUINTE DERIVADO: um estudo a partir da Constituição do Estado do Rio Grande do Sul de $1989^{1}$
}

\author{
Albenir Itaboraí Querubini Gonçalves ${ }^{2}$ \\ Marcos Roberto de Lima Aguirre ${ }^{3}$
}

RESUMO: O presente trabalho tem por finalidade realizar reflexões a partir das características gerais do poder constituinte dos Estados-membros, a fim de formular possíveis deduções sobre os limites ao poder constitucional derivado decorrente no vigente modelo federativo brasileiro.

PALAVRAS-CHAVE: Constituição. Constituição dos Estados-membros. Limites do Poder Constituinte Derivado. Federalismo.

\author{
"FOUNDAMENTAL RIGHTS AND GUARANTEES" IN THE STATES OF THE \\ FEDERATION CONSTITUTIONS AND THE LIMITS OF THE LEGISLATIVE \\ BRANCH CONSTITUTIONAL REFORM POWER: a study of the Constitution of the \\ Rio Grande do Sul state
}

\begin{abstract}
The present work has as its objective to make an analysis of the general characteristis of the constitutional reform power of the federated stats, in order to stablish possible conclusions over the limits of the constitutional reform power of the legislative branch in the brazillian federation.

KEY-WORDS: Constitution. Federated states constitution. Legislative branch constitutional reform power limits. Federalism.

SUMÁRIO: 1. Introdução, 2. Características gerais do poder constituinte derivado dos Estados-membros, 3. A previsão "dos direitos e garantias fundamentais" na Constituição do Estado do Rio Grande do Sul, 4. Questões decorrentes da análise entre as constituições estaduais quanto à previsão de direitos e garantias fundamentais, 5 . Em busca de respostas sobre os limites ao poder constitucional derivado decorrente no vigente modelo federativo brasileiro, 6. Considerações finais, 7. Bibliografia.
\end{abstract}

\footnotetext{
${ }^{1}$ O presente artigo é síntese de apresentação realizada para a Disciplina "Seminários de Direito do Estado: A Constituição do Estado do Rio Grande do Sul", ministrada pelo Prof. Dr. Cezar Saldanha Souza Junior, no $1^{\circ}$ semestre do ano letivo de 2009 do Programa de Pós-Graduação em Direito da Faculdade de Direito da Universidade Federal do Rio Grande do Sul.

${ }^{2}$ Bacharel em Ciências Jurídicas e Sociais pela Universidade Federal de Santa Maria - UFSM. Especialista em Direito Ambiental e Mestrando pela Universidade Federal do Rio Grande do Sul - UFRGS. E-mail: albenir@gmail.com.

3 Bacharel em Ciências Jurídicas e Sociais pela Pontifícia Universidade Católica do Rio Grande do Sul PUCRS. Especialista em Direito do Estado pela Universidade Federal do Rio Grande do Sul - UFRGS. Advogado. E-mail: mrla81@gmail.com.
} 


\section{INTRODUÇÃO}

O presente estudo tem por finalidade realizar reflexões sobre os limites do poder constituinte dos Estados-membros no atual modelo federativo existente no Brasil no que se refere às disposições sobre direitos e garantias fundamentais, possuindo como foco central a análise das disposições da Constituição do Estado do Rio Grande do Sul.

A problemática gira em torno de questões advindas da relação entre os Estadosmembros e a União quando do exercício do poder constituinte derivado, pois da análise das tensões que surgem na prática pode-se revelar a tendência do atual modelo federativo brasileiro - se mais voltada a uma posição centralizada ou, por outro lado, se tendendo a uma posição descentralizadora.

Para alcançar tais fins, o ponto de partida será a comparação das disposições sobre direitos e garantias fundamentais previstos na Constituição do Estado do Rio Grande do Sul com o rol de direitos e garantias trazido pela Constituição da República e com aqueles constantes nas Constituições de outros Estados-membros.

A análise será também delineada levando em consideração as características gerais do poder constituinte dos Estados-membros que são apontadas pela doutrina e o entendimento que vem sendo adotado pelo Supremo Tribunal Federal nos julgados sobre a matéria.

\section{CARACTERÍSTICAS GERAIS DO PODER CONSTITUINTE DERIVADO DOS ESTADOS-MEMBROS}

O Ato das Disposições Constitucionais Transitórias da Constituição da República Federativa do Brasil de 1988 previu em seu artigo 11 que cada Assembléia Legislativa, com poderes constituintes, teria o prazo de um ano, contado da promulgação da Constituição da República para elaborar a Constituição do Estado-membro da federação brasileira ${ }^{4}$.

Por sua vez, a Constituição da República Federativa do Brasil de 1988, ao tratar dos Estados Federados, previu, em seu artigo 25, que os Estados-membros organizam-se e regemse pelas Constituições e leis que adotarem, desde que sejam observados os princípios da Constituição da República, declarando que são reservadas aos Estados-membros as

\footnotetext{
4 Texto constante no Ato das Disposições Constitucionais Transitórias da Constituição da República Federativa do Brasil de 1988: “Art. 11. Cada Assembléia Legislativa, com poderes constituintes, elaborará a Constituição do Estado, no prazo de um ano, contado da promulgação da Constituição Federal, obedecidos os princípios desta".
} 
competências que não lhe sejam vedados, conforme consta no parágrafo $1^{\circ}$ do referido artigo, cujas disposições seguem transcritas:

Art. 25. Os Estados organizam-se e regem-se pelas Constituições e leis que adotarem, observados os princípios desta Constituição.

$\S 1^{\circ}$ - São reservadas aos Estados as competências que não lhes sejam vedadas por esta Constituição.

Inicialmente, ressalve-se que a doutrina majoritariamente classifica o poder constituinte em duas espécies: o poder constituinte originário e o poder constituinte derivado. O primeiro deles, o poder originário, possui como características ser um poder inicial, ilimitado, autônomo e incondicionado. Por sua vez, o poder constituinte derivado é subdividido em poder constituinte reformador e poder constituinte decorrente, cada um com características próprias. O poder constituinte derivado reformador é aquele previsto pela própria Constituição para fins de alteração do texto constitucional, sendo exemplos as Emendas Constitucionais. Já o poder constituinte derivado decorrente é aquele típico dos Estados-membros, o qual permite a tais entes auto-organização e autorregulação em seus territórios ${ }^{5}$.

Conforme explica Alexandre de Moraes, o poder constituinte derivado decorrente, o qual daqui para diante será chamado simplesmente de poder constituinte derivado, "consiste na possibilidade que os Estados-membros têm, em virtude de sua autonomia políticoadministrativa, de se auto-organizarem por meio de suas respectivas constituições estaduais"6.

A partir de uma leitura do artigo "Poder constituinte do Estado-Membro", de autoria do professor Raul Machado Horta, catedrático da Faculdade de Direito da Universidade Federal de Minas Gerais, é possível enumerar as seguintes características do poder constituinte dos Estados-membros: (a) possui como fonte jurídica a Constituição da República, (b) sempre será derivado e secundário, (c) Surge em período sucessivo e (d) é $\operatorname{limitado}^{7}$.

Em que pese as Constituições dos Estados-membros caracterizarem-se como "a expressão mais elevada do exercício concreto do poder de auto-organização deferido aos

\footnotetext{
${ }^{5}$ Sobre o poder constituinte, vide: FERREIRA FILHO, Manoel Gonçalves. Curso de Direito Constitucional, pp. 20-32.

${ }^{6}$ MORAES, Alexandre de. Curso de Direito Constitucional, p. 29. Quanto à natureza do poder constituinte derivado decorrente, pode-se dizer que é um poder indireto ou de segundo grau que serve para reformar uma Constituição já existente, dentro das regras e matérias por ela previstas. FERREIRA FILHO, Manoel Gonçalves. Curso de Direito Constitucional, pp. 28-29.

${ }^{7}$ HORTA, Raul Machado. Poder Constituinte do Estado-membro. Revista de Direito Público. São Paulo: Revista dos Tribunais, n. 88/1988, pp. 05-17.
} 
Estados-membros pela Lei Fundamental", conforme expôs o Min. Celso de Mello, no julgamento da Ação Direta de Inconstitucionalidade nº 486/DF, seu exercício é juridicamente limitado às condições impostas pela própria Constituição.

O professor Manoel Gonçalves Ferreira Filho também denomina o poder constituinte derivado decorrente dos Estados-membros como "poder constituinte instituído", por decorrência de suas características de subordinação, secundariedade e condicionalidade em relação à Constituição da República, uma vez que o constituinte estadual somente pode agir validamente dentro dos limites autorizados pelo poder constituinte originário ${ }^{8}$.

Cumpre observar que é justamente em razão das características do poder constituinte derivado dos Estados-membros, em especial a sua subordinação direta à Constituição da República, é que tal poder pode vir a ser objeto de controle de constitucionalidade. Nas palavras do professor Raul Machado Horta, "a precedência da Constituição Federal [leia-se Constituição da República ou Lei Fundamental], sobre a do Estado-membro é exigência lógica da organização federal, e essa procedência, que confere validez ao sistema federal, imprime a força de matriz originária ao constituinte federal e faz do constituinte um seguimento derivado daquele" $"$.

Feitas tais considerações cumpre agora analisar como se comportou o constituinte gaúcho em relação à previsão "dos direitos e garantias fundamentais" constante na Constituição do Estado do Rio Grande do Sul de 1989.

\section{A PREVISÃO "DOS DIREITOS E GARANTIAS FUNDAMENTAIS" NA CONSTITUIÇÃO DO ESTADO DO RIO GRANDE DO SUL}

Após o seu preâmbulo, a Constituição do Estado do Rio Grande do Sul, de 3 de outubro de 1989, traz expressamente em seu Título I, denominado "Dos Princípios Fundamentais", a proclamação de direitos e garantias fundamentais a serem observados no território do Estado do Rio Grande do Sul.

Assim dispõe a Constituição do Estado do Rio Grande do Sul de 1989, em seu Título I:

\footnotetext{
${ }^{8}$ FERREIRA FILHO, Manoel Gonçalves. Curso de Direito Constitucional, p. 28. Sua força, como deixa claro o professor Manoel Gonçalves Ferreira Filho, "não provêm de si próprio, mas do poder constituinte originário, sendo por ele criado. Tendo em vista ser um poder derivado, sofre restrições, estando condicionado e subordinado ao seu criador”. FERREIRA FILHO, Manoel Gonçalves. O Poder Constituinte, p. 112.

${ }^{9}$ HORTA, Raul Machado. Poder Constituinte do Estado-membro, p. 7.
} 
Art. $1^{o}$ - O Estado do Rio Grande do Sul, integrante com seus Municípios, de forma indissolúvel, da República Federativa do Brasil, proclama e adota, nos limites de sua autonomia e competência, os princípios fundamentais e os direitos individuais, coletivos, sociais e políticos universalmente consagrados e reconhecidos pela Constituição Federal a todas as pessoas no âmbito de seu território.

Art. $2^{o}$ - A soberania popular será exercida por sufrágio universal e pelo voto direto e secreto, com igual valor para todos e, nos termos da lei, mediante:

I-plebiscito;

II - referendo;

III - iniciativa popular.

No que se refere aos direitos e garantias fundamentais, foco do presente estudo, observa-se que a Constituição do Estado do Rio Grande do Sul faz expressa remissão ao rol de direitos e garantias previstos na Constituição da República. Nesse sentido não há quaisquer inovações por parte do constituinte gaúcho. De outra forma, apenas podemos encontrar disposições diferentes daquelas constantes na Constituição da República no que se refere às disposições sobre o meio ambiente ${ }^{10}$, lembrado que o direito ao meio ambiente sadio e equilibrado é considerado um direito fundamental, conforme reconheceu o próprio Supremo Tribunal Federal ${ }^{11}$.

A Constituição do Estado do Rio Grande do Sul, seguindo a linha da maioria das Constituições dos demais Estados-membros da Federação Brasileira, em nada inova no que se refere aos direitos e garantias fundamentais. A respeito do assunto, em linhas gerais, podem as Constituições dos Estados-membros serem classificadas da seguinte forma: (a) Constituições Estaduais que não fazem referência aos direitos e garantias fundamentais, assim consideradas pela ausência de título ou capítulo específico a tal matéria; (b) Constituições Estaduais que apenas remetem ao rol da Constituição da República; e (c) Constituições Estaduais que preveem outras disposições quanto aos direitos e garantias fundamentais, assim consideradas aquelas que inovam no tratamento dos direitos e garantias fundamentais em relação à Constituição da República.

De acordo com a classificação aqui proposta, em linhas gerais, assim organizam-se as Constituições dos Estados-membros da Federação Brasileira:

\footnotetext{
${ }^{10}$ Vide o Capitulo IV do Título VII da Constituição do Estado do Rio Grande do Sul, artigos 250 a 259.

${ }^{11}$ Sobre o assunto, vide os seguintes julgados do Supremo Tribunal Federal: ADI n ${ }^{\circ}$ 3.540-MC, Rel. Min. Celso de Mello, julgamento em $1^{\circ} .09 .2005$, publicado no Diário da Justiça de 03.02.2006 e MS no 22.164, Rel. Min. Celso de Mello, julgamento em 30.10.1995, publicado no Diário da Justiça de 17.11.1995.
} 


\begin{tabular}{|c|c|c|}
\hline $\begin{array}{l}\text { Constituições Estaduais } \\
\text { que não fazem referência } \\
\text { aos direitos e garantias } \\
\text { fundamentais }\end{array}$ & $\begin{array}{l}\text { Constituições Estaduais } \\
\text { que apenas remetem ao rol } \\
\text { da Constituição da } \\
\text { República }\end{array}$ & $\begin{array}{l}\text { Constituições Estaduais } \\
\text { que inovam em relação à } \\
\text { Constituição da República } \\
\text { (já com os referidos artigos) }\end{array}$ \\
\hline $\begin{array}{c}\text { Acre } \\
\text { Ceará } \\
\text { Goiás } \\
\text { Pernambuco } \\
\text { Rondônia } \\
\text { São Paulo } \\
\text { Tocantins }\end{array}$ & $\begin{array}{c}\text { Rio Grande do Sul } \\
\text { Maranhão } \\
\text { Mato Grosso do Sul } \\
\text { Minas Gerais } \\
\text { Pará } \\
\text { Paraíba } \\
\text { Paraná } \\
\text { Rio Grande do Norte } \\
\text { Roraima } \\
\text { Santa Catarina }\end{array}$ & $\begin{array}{c}\text { Alagoas (Arts. } 1^{\circ} \text { a } 3^{\circ} \text { ) } \\
\text { Amapá (art. } 4^{\circ} \text { a } 5^{\circ}-\mathrm{E} \text { ) } \\
\text { Amazonas (art. } 3^{\circ} \text { a } 8^{\circ} \text { ) } \\
\text { Bahia (art. } 4^{\circ} \text { ) } \\
\text { Espírito Santo (art. } 3^{\circ} \text { a } 9^{\circ} \text { ) } \\
\text { Mato Grosso (art. 10) } \\
\text { Piauí (art. } 5^{\circ} \text { a } 9^{\circ} \text { ) } \\
\text { Rio de Janeiro (art. } 3^{\circ} \text { a } 38 \text { ) } \\
\text { Sergipe (art. } 3^{\circ} \text { a } 5^{\circ} \text { ) }\end{array}$ \\
\hline
\end{tabular}

Daquilo que se observa da classificação proposta, evidencia-se a inexistência de uma uniformidade normativa das Constituições Estaduais, que, diga-se de passagem, não se limita apenas ao campo dos direitos e garantias fundamentais. Tal fato, por consequência, gera algumas indagações a respeito do grau de inovação que os Estados-membros possam vir a ter no âmbito da sua auto-organização, tendo-se em vista as características limitadas do poder constituinte derivado dos Estados-membros, o que traz à tona a problemática da validade de tais disposições inovadoras em razão da subordinação direta à Constituição da República.

\section{QUESTÕES DECORRENTES DA ANÁLISE ENTRE AS CONSTITUIÇÕES ESTADUAIS QUANTO À PREVISÃO DE DIREITOS E GARANTIAS FUNDAMENTAIS}

Diante da constatação da existência de diferentes tratamentos dados pelas Constituições dos Estados-membros, e em especial atenção àquelas que trazem disposições inovadoras em relação à Constituição da República, podem surgir algumas indagações práticas, a exemplo: 
$1^{\text {a }}$ Questão: no que se refere ao poder constituinte do Estado-membro com relação aos direitos e garantias fundamentais, o Estado-membro poderia reduzir ou ampliar o rol de garantias além daqueles previstos pela Constituição da República?

$2^{\mathbf{a}}$ Questão: em casos afirmativos, podendo haver ampliações ou inovações no que se refere aos direitos e garantias fundamentais em relação àquelas disposições previstas pela Constituição da República, quais seriam os limites inovadores do poder constitucional dos Estados-membros para que tais previsões sejam consideradas válidas?

$3^{\mathbf{a}}$ Questão: havendo conflitos entre as disposições trazidas pela Legislação Nacional ou Federal e a Constituição Estadual quais disposições devem prevalecer?

\section{EM BUSCA DE RESPOSTAS SOBRE OS LIMITES AO PODER CONSTITUCIONAL DERIVADO DECORRENTE NO VIGENTE MODELO FEDERATIVO BRASILEIRO}

Em resposta à primeira indagação, sobre a possibilidade do poder constituinte derivado dos Estados-membros reduzir ou ampliar o rol de garantias além daqueles previstos pela Constituição da República, a primeira resposta é negativa quanto à possibilidade de haver uma redução dos direitos e garantias fundamentais, pois nessa hipótese se estaria contrariando a Constituição da República. Quanto à possibilidade de ampliação, a resposta tende a ser afirmativa, uma vez que a Constituição da República permite aos Estados-membros organizarem-se e regerem-se pelas suas Constituições e leis próprias, desde que observados os princípios da Constituição da República e as competências por ela reservadas aos Estadosmembros, conforme se extrai da leitura do art. 25 e seu parágrafo primeiro. Ademais, considerando que a Constituição da República não proíbe o uso de Emendas às Constituições Estaduais pelos Estados-membros, é teórica e juridicamente possível que a inovação das disposições sobre direitos e garantias nas Constituições Estaduais também possa se dar em momento posterior a sua promulgação, por meio de Emendas Constitucionais. Um bom exemplo prático seria em relação às disposições sobre direito ao meio ambiente, cuja proteção ambiental pode ser ampliada por meio de Emenda à Constituição Estadual. 
Nesse sentido, a questão da validade das disposições inovadoras é diretamente relacionada com a segunda indagação, já que tudo indica que não há óbices quanto à possibilidade de vir o Estado-membro a ampliar o rol de direitos. Mas o fato de a Constituição Estadual poder inovar não quer dizer que tal possibilidade possa se dar forma ilimitada. Eis aqui a grande problemática a ser enfrentada, pois é difícil precisar quais os limites do poder constituinte derivado, uma vez que não existem respostas definidas e muito vai depender do entendimento do Supremo Tribunal Federal manifestado em cada caso levado a juízo. Logo, a primeira barreira a uma tentativa de construção de parâmetros quanto aos referidos limites dependem diretamente daquilo que o Supremo Tribunal Federal entender como possível ou não de se inovar, o que pode vir a ser um risco contra o próprio modelo federativo, na medida em que suas decisões podem vir a favorecer um centralismo de poder da União em detrimento dos Estados-mebros ${ }^{12}$.

Nesse sentido, qualquer tentativa de esboçar parâmetros sobre as limitações do poder constituinte dos Estados-membros deve se pautar a partir dos precedentes daquela Corte. Em linhas gerais, pode-se dizer que o Supremo Tribunal Federal vem adotando como regra geral o chamado "princípio da simetria", que parte do raciocínio que deve haver um paralelismo entre as disposições da Constituição da República e as disposições das Constituições dos Estadosmembros. Um exemplo disso é o entendimento do Supremo Tribunal Federal manifestado na Ação Direta de Inconstitucionalidade $n^{\circ} 486$, ao concluir que não poderia a Constituição Estadual adotar quorum diverso daquele previsto na Constituição da República para o processo de reforma da Constituição Estadual ${ }^{13}$.

Dentre as limitações do poder constituinte estadual está o dever de respeitar os princípios fundamentais da República Federativa, tais como a soberania, a cidadania, a dignidade da pessoa humana e os valores sociais do trabalho e da livre iniciativa (art. $1^{\circ}$ da Constituição da República). Nesse sentido, não pode, por exemplo, a Constituição do Estadomembro prever uma ampliação do direito ao meio ambiente de forma que inviabilize por

\footnotetext{
${ }^{12}$ Sobre o assunto, vide: LEAL, Roger Stiefelmann. A autonomia do estado-membro e o papel do Supremo Tribunal Federal. Página Web do Programa de Pós-Graduação em Direito da UFRGS. Disponível em: <http://www6.ufrgs.br/ppgd/doutrina/leal3.htm>.

13 "Processo de reforma da Constituição estadual - Necessária observância dos requisitos estabelecidos na Constituição Federal (art. 60, $\S \S 1^{\circ}$ a $5^{\circ}$ ) - Impossibilidade constitucional de o Estado-Membro, em divergência com o modelo inscrito na Lei Fundamental da República, condicionar a reforma da Constituição estadual à aprovação da respectiva proposta por 4/5 (quatro quintos) da totalidade dos membros integrantes da Assembléia Legislativa - Exigência que virtualmente esteriliza o exercício da função reformadora pelo Poder Legislativo local - A questão da autonomia dos Estados-Membros (CF, art. 25) - Subordinação jurídica do poder constituinte decorrente às limitações que o órgão investido de funções constituintes primárias ou originárias estabeleceu no texto da Constituição da República: (....)." (ADI nº 486, Rel. Min. Celso de Mello, julgamento em 03.04.1997, DJ de 10.11.2006)
} 
completo a exploração da propriedade privada, atentando diretamente contra a livre iniciativa. A partir de tal exemplo, evidencia-se que as eventuais inovações também se devem pautar por critérios de razoabilidade e bom-senso.

Expõe Raul Machado Horta que "as normas centrais da Constituição Federal [leia-se Constituição da República], tenham elas a natureza de princípios constitucionais, de princípios estabelecidos e de normas de preordenação, afetam a liberdade criadora do poder constituinte e acentuam o caráter derivado desse poder" ${ }^{\prime 4}$. Desta forma, não pode o Estadomembro inovar ao ponto de contrariar os princípios federativos constantes na Constituição da República. Um exemplo clássico nesse sentido é o da Representação no 94, em que o Supremo Tribunal Federal declarou inconstitucional a Constituição do Estado do Rio Grande do Sul de 1947, manifestando o entendimento pela impossibilidade da previsão de regras parlamentaristas na Constituição Estadual por ofensa ao principio nuclear da independência e da harmonia dos Poderes, ressaltando que a homogeneidade do regime político da federação impõe a identidade de governo na União e nos Estados-membros ${ }^{15}$.

O artigo 19 da Constituição da República traz vedações que também são limitações ao poder constituinte dos Estados-membros. Segundo o referido artigo, é vedado à União, aos Estados e aos Municípios: (a) “estabelecer cultos religiosos ou igrejas, subvencioná-los, embaraçar-lhes o funcionamento ou manter com eles ou seus representantes relações de dependência ou aliança, ressalvada, na forma da lei, a colaboração de interesse público"; (b) "recusar fé aos documentos públicos"; e, (c) “criar distinções entre brasileiros ou preferências entre si”.

Outra limitação ao poder constituinte derivado decorrente diz respeito à competência das matérias não reservadas aos Estados-membros, a exemplo da não possibilidade do Estadomembro dispor sobre matéria de interesse local do Município. É o que se pode concluir a partir do entendimento do Supremo Tribunal Federal no julgamento da Ação Direta de Inconstitucionalidade $\mathrm{n}^{\circ} 1.221 / \mathrm{RJ}$. No presente caso, foi declarada a inconstitucionalidade do art. 13 da Constituição Estadual do Rio de Janeiro de 1989, bem como da Lei Estadual do Estado do Rio de Janeiro n ${ }^{\circ}$ 2.007/1992, que regulamentava o referido artigo constitucional, o qual previa, entre o rol de direitos e garantias fundamentais, a gratuidade de sepultamento e dos procedimentos a ele necessários, inclusive com o fornecimento de esquife, para todos os que percebem até um salário mínimo, os desempregados e os reconhecidamente pobres. $\mathrm{Na}$ hipótese, o Supremo Tribunal Federal entendeu que pelo fato dos serviços funerários

\footnotetext{
${ }^{14}$ HORTA, Raul Machado. Poder Constituinte do Estado-membro, p. 10.

${ }^{15}$ HORTA, Raul Machado. Poder Constituinte do Estado-membro, pp. 14-15.
} 
constituírem serviços de interesse dos Municípios (art. 30, inc. V, da Constituição da República de 1988), não poderia ter o Estado-membro ter inovado em tal previsão. Assim, conclui-se que o poder constituinte dos Estados-membros deve observar como limites as competências das matérias reservadas privativamente aos outros entes da Federação. No entanto, a partir dessa linha de raciocínio, poderia o poder constituinte do Estado-membro inovar nas hipóteses em que lhe é conferida competência comum (art. 23 da Constituição da República ${ }^{16}$ ) e nas hipóteses em que é prevista competência legislativa concorrente, neste último caso desde que observados os termos disciplinados no art. 24 e parágrafos da Constituição da República ${ }^{17}$.

Por fim, uma resposta à terceira indagação formulada, em saber qual disposição prevaleceria na hipótese de conflitos entre as disposições trazidas pela Legislação Nacional ou Federal ${ }^{18}$ e a Constituição Estadual, tende a observar, principalmente, as questões relativas às competências legislativas atribuídas a cada ente federado. Desta feita, a conclusão tende a ser formulada no sentido de que as disposições da Constituição Estadual vão prevalecer sempre

${ }^{16}$ Consta no referido artigo: "Art. 23. É competência comum da União, dos Estados, do Distrito Federal e dos Municípios: I - zelar pela guarda da Constituição, das leis e das instituições democráticas e conservar o patrimônio público; II - cuidar da saúde e assistência pública, da proteção e garantia das pessoas portadoras de deficiência; III - proteger os documentos, as obras e outros bens de valor histórico, artístico e cultural, os monumentos, as paisagens naturais notáveis e os sítios arqueológicos; IV - impedir a evasão, a destruição e a descaracterização de obras de arte e de outros bens de valor histórico, artístico ou cultural; V - proporcionar os meios de acesso à cultura, à educação e à ciência; VI - proteger o meio ambiente e combater a poluição em qualquer de suas formas; VII - preservar as florestas, a fauna e a flora; VIII - fomentar a produção agropecuária e organizar o abastecimento alimentar; IX - promover programas de construção de moradias e a melhoria das condições habitacionais e de saneamento básico; X - combater as causas da pobreza e os fatores de marginalização, promovendo a integração social dos setores desfavorecidos; XI - registrar, acompanhar e fiscalizar as concessões de direitos de pesquisa e exploração de recursos hídricos e minerais em seus territórios; XII - estabelecer e implantar política de educação para a segurança do trânsito. Parágrafo único. Leis complementares fixarão normas para a cooperação entre a União e os Estados, o Distrito Federal e os Municípios, tendo em vista o equilíbrio do desenvolvimento e do bem-estar em âmbito nacional. (Redação dada pela Emenda Constitucional no 53, de 2006)"

17 "Art. 24. Compete à União, aos Estados e ao Distrito Federal legislar concorrentemente sobre: I - direito tributário, financeiro, penitenciário, econômico e urbanístico; II - orçamento; III - juntas comerciais; IV - custas dos serviços forenses; V - produção e consumo; VI - florestas, caça, pesca, fauna, conservação da natureza, defesa do solo e dos recursos naturais, proteção do meio ambiente e controle da poluição; VII - proteção ao patrimônio histórico, cultural, artístico, turístico e paisagístico; VIII - responsabilidade por dano ao meio ambiente, ao consumidor, a bens e direitos de valor artístico, estético, histórico, turístico e paisagístico; IX educação, cultura, ensino e desporto; X - criação, funcionamento e processo do juizado de pequenas causas; XI procedimentos em matéria processual; XII - previdência social, proteção e defesa da saúde; XIII - assistência jurídica e Defensoria pública; XIV - proteção e integração social das pessoas portadoras de deficiência; XV proteção à infância e à juventude; XVI - organização, garantias, direitos e deveres das polícias civis. $\S 1^{\circ}$ - No âmbito da legislação concorrente, a competência da União limitar-se-á a estabelecer normas gerais. $\S 2^{\mathrm{o}}-\mathrm{A}$ competência da União para legislar sobre normas gerais não exclui a competência suplementar dos Estados. $\S 3^{\circ}$ - Inexistindo lei federal sobre normas gerais, os Estados exercerão a competência legislativa plena, para atender a suas peculiaridades. $\S 4^{\circ}$ - A superveniência de lei federal sobre normas gerais suspende a eficácia da lei estadual, no que the for contrário".

18 Sobre as distinções entre normas nacionais e federais, vide: ATALIBA, Geraldo. Regime Constitucional e Leis Nacionais e Federais. Revista de Direito Público. São Paulo: Revista dos Tribunais, n. 53/54, jan./jun., 1980, pp. 58-76. 
quando os conflitos disserem respeito a matérias típicas dos Estados-membros. No entanto, não pode ser esquecido que a palavra final sobre o assunto dependerá do entendimento do Supremo Tribunal Federal, de acordo com a análise dos casos concretos.

\section{CONSIDERAÇÕES FINAIS}

A abordagem aqui realizada, a qual possui como pretensão dar início ao debate em torno das discussões a respeito do tema, permitiu realizar deduções sobre os limites ao poder constitucional derivado decorrente no vigente modelo federativo brasileiro. Em suma, deduziu-se que o poder constituinte dos Estados-membros deve: (a) respeitar os princípios fundamentais da Federação (ex.: não pode contrariar o modelo de regime estabelecido pela Constituição da República); (b) observar as proibições trazidas pela Constituição da República (a exemplo daquelas contidas no art. 19); (c) observar a competência das matérias reservadas aos Estados-membros; (d) observar as regras referentes à competência legislativa comum e concorrente (art. 23 e 24 da Constituição da República); e, (e) pautar-se por critérios de razoabilidade e bom-senso.

No entanto, referidas conclusões não podem ser tomadas como sendo regras fixas, uma vez que as questões aqui levantadas ainda carecem de reflexões por parte da doutrina e da jurisprudência. Ademais, ao tentar deduzir as respostas sobre os limites do poder constituinte dos Estados-membros, restou evidenciado que as respostas definitivas sobre a temática serão dadas pelo Judiciário, destacando-se, assim, a grande responsabilidade do Supremo Tribunal Federal em dizer quais são esses limites. Resta aqui uma questão delicada e que necessita de atenções por parte dos juristas brasileiros, uma vez que a adoção de posturas voltadas ao centralismo do poder, o que de fato pode ser observado nos entendimentos manifestados pelo Supremo Tribunal Federal sobre a matéria, em sua maioria embasados pelo chamado "principio da simetria", acaba por desprestigiar a liberdade de inovação dos Estadosmembros quando do exercício da sua auto-organização.

Por fim, diante da constatação do atual quadro de centralismo do poder no nosso modelo federalista, aqui evidenciado, cumpre concluir que na presente data de celebração dos 20 anos das constituições dos Estados-membros, infelizmente, restam mais motivos para se refletir do que aqueles para se comemorar! 


\section{REFERÊNCIAS BIBLIOGRÁFICAS}

ATALIBA, Geraldo. Regime Constitucional e Leis Nacionais e Federais. Revista de Direito Público. São Paulo: Revista dos Tribunais, n. 53/54, jan./jun., 1980, pp. 58-76.

\section{ESTADO DO RIO GRANDE DO SUL. Constituição do Estado do Rio Grande do}

Sul. Texto constitucional de 3 de outubro de 1989 com as alterações adotadas pelas Emendas Constitucionais de $\mathrm{n}^{\circ}$ 1, de 1991, a 57, de 2008. Atualizada pelo Departamento de Assessoramento Legislativo - Superintendência Legislativa - Assembléia Legislativa do Estado do Rio Grande do Sul. Disponível em: <http://www.al.rs.gov.br/prop/legislacao/constituicao/>.

FERREIRA FILHO, Manoel Gonçalves. Curso de Direito Constitucional. 31. ed. São Paulo: Saraiva, 2005.

FERREIRA FILHO, Manoel Gonçalves. O Poder Constituinte. 3. ed. São Paulo: Saraiva, 1999.

HORTA, Raul Machado. Poder Constituinte do Estado-membro. Revista de Direito Público. São Paulo: Revista dos Tribunais, n. 88/1988, pp. 05-17.

LEAL, Roger Stiefelmann. A autonomia do estado-membro e o papel do Supremo Tribunal Federal. Página Web do Programa de Pós-Graduação em Direito da UFRGS. Disponível em: <http://www6.ufrgs.br/ppgd/doutrina/leal3.htm>, acesso em 16 de maio de 2009.

MORAES, Alexandre de. Curso de Direito Constitucional. 24. ed. São Paulo: Atlas, 2009.

SOUZA JUNIOR, Cezar Saldanha; AVILA, Marta Marques (coord.). Direito do Estado - Estudos sobre Federalismo. Porto Alegre: Dora Luzzatto, 2007. 